Original Article

\title{
Changes in exercise tolerance and quality of life are unrelated in lung cancer survivors who undergo video-assisted thoracic surgery
}

\author{
Kunihiko Anami, RPT, MS ${ }^{1,2)^{*} \text {, Jun Horie, RPT, PhD }}{ }^{3)}$, Yoshiyasu Hirayama, RPT ${ }^{4}$, \\ NaOKi Yamashita, MD, PhD ${ }^{5}$, Kenichi Ito, RPT, $\mathrm{PhD}^{6)}$ \\ 1) Department of Rehabilitation, Faculty of Allied Health, Yamato University: Suita, Osaka 564-0082, \\ Japan \\ 2) Graduate School of Comprehensive Rehabilitation, Osaka Prefecture University, Japan \\ 3) Department of Physical Therapy, Faculty of Health Science, Kyoto-Tachibana University, Japan \\ 4) Department of Rehabilitation, Mitsubishi Kyoto Hospital, Japan \\ 5) Department of Thoracic Surgery, Mitsubishi Kyoto Hospital, Japan \\ 6) Department of Rehabilitation, Hirakata Kohsai Hospital, Japan
}

\begin{abstract}
Purpose] The associations between changes in respiratory function, exercise tolerance, and quality of life (QOL) in patients with lung cancer who undergo lobectomy using video-assisted thoracoscopic surgery (VATS) are unclear. This study aimed to investigate the relationships between exercise tolerance and QOL in patients who underwent VATS. [Subjects and Methods] Thirty-six patients with lung cancer were followed for 3 months after VATS. Patients were evaluated before and 1, 4, and 12 weeks after surgery. Respiratory function, grip strength, and knee extension strength, as well as the results of timed up and go, 6-minute walk, and cardiopulmonary exercise tests, were evaluated using the 36-item short-form health survey. Longitudinal changes in physical performance and QOL were analyzed, as was the relationship between the change in physical function and QOL. [Results] The physical and social aspects of QOL significantly decreased at week 4 post-surgery, but recovered to pre-surgical levels by week 12. In contrast, physical (non-respiratory) function recovered to pre-surgical levels by week 4 . There was no correlation between the percentages of change in QOL and those related to physical function. [Conclusion] Our preliminary study highlights the fact that early recovery of physical function is possible after VATS, but does not necessarily correlate with early QOL recovery. It is therefore necessary to perform perioperative interventions to promptly restore QOL after surgery.

Key words: Video-assisted thoracic surgery, Exercise tolerance, Quality of life
\end{abstract}

(This article was submitted Nov. 28, 2017, and was accepted Dec. 22, 2017)

\section{INTRODUCTION}

Recent trends in lung cancer care have improved survival rates owing to advances in diagnosis and treatment techniques; however, lung cancer is still a top cause of cancer-related death ${ }^{1)}$. Lobectomy is the most effective treatment for early-stage lung cancer, and is commonly performed via minimally invasive video-assisted thoracoscopic surgery (VATS) ${ }^{2-5)}$. The advantage of this method is that the number of hospitalization days is shorter than if thoracotomy is performed ${ }^{6}$; this lowers the incidence of postoperative complications ${ }^{7)}$ and improves the 5 year survival rate ${ }^{8)}$. The spread of VATS has enabled curative therapy for patients who are elderly or have poor lung function ${ }^{9,10)}$.

Postoperative physical therapy has clear benefits, as exemplified by a community program implemented by Edvardsen et

*Corresponding author. Kunihiko Anami (E-mail: anami.kunihiko@yamato-u.ac.jp)

(C)2018 The Society of Physical Therapy Science. Published by IPEC Inc.

(c) (1) $\odot$ This is an open-access article distributed under the terms of the Creative Commons Attribution Non-Commercial No Deriva-

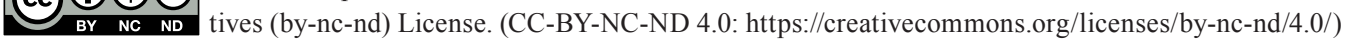


al. following hospital discharge ${ }^{11)}$. In Japan, however, the groundwork has yet to be laid for physical therapy following hospital discharge. Physical therapy is performed during the perioperative period, and the desired approach is one that focuses not only on major survival-related medical indices but also on the postoperative quality of life (QOL) ${ }^{12}$. Although the QOL is known to decrease post-surgery ${ }^{13}{ }^{14}$, the factors causing it to decline are unclear, and QOL improvement programs have yet to be established.

The identification of factors causing QOL to decline might lead to the development of effective physical therapy programs for VATS patients. This requires examining the association between exercise tolerance and QOL in lung cancer survivors. In this study, we investigated the natural recovery timeline over a 12-week period in patients who had only undergone physical therapy while hospitalized with the aim of identifying the areas on which physical therapy should focus while patients are still hospitalized.

\section{SUBJECTS AND METHODS}

This was a prospective study of the pre-surgical period as well as 1, 4, and 12 weeks post-surgery. The study was approved by the Osaka Prefecture University Research Ethics Committee, Osaka, Japan (2014/2014-122).

Patients who were scheduled for lung surgery were included in the study. A total of 47 patients were initially enrolled, 36 of whom we were evaluable for the 3-month duration of the study. In accordance with the Declaration of Helsinki, patients received written and verbal explanations of the research plan in advance, and each provided written consent to participate. Patients who were excluded were those with dementia, apparent motor paralysis, painful bone and joint diseases, and severe medical comorbidities.

Preoperative education was conducted to prevent otherwise likely impairment of postoperative respiratory function, decreased physical function, and postoperative complications. Additionally, we provided instructions for perioperative management such as early mobilization and respiratory exercise. After surgery, physical therapy was performed in the ward from the first day after surgery. Postoperative guidance involved walking exercises and bicycle ergometer exercises aimed at improving exercise tolerance. Although we designed and provided instructions regarding home rehabilitation programs, the implementation rate was unclear. None of the subjects received outpatient physical therapy.

The evaluated parameters included the respiratory function, grip strength, knee extension strength; and timed up and go (TUG) test, 6-minute walking distance test (6MWT), cardiopulmonary exercise test (CPX), and short-form 36-item health survey (SF-36) results.

A spirometer manufactured by Minato Medical Science Co., Ltd. (Osaka, Japan) was used for the respiratory function test; the flow volume was measured at least twice, and the best value was adopted. The grip strength was measured with a digital grip force meter manufactured by Takei Instrumentation Industry (Tokyo, Japan). The knee extension strength was measured with a handheld dynamometer manufactured by Anima Co., Ltd (Tokyo, Japan), the value was normalized to the percentage of body weight. The tests were performed twice on both sides, and the larger values were adopted. TUG was measured upon walking "as fast as possible"15). From an initial position seated on a $40 \mathrm{~cm}$-high armrest chair, patients were twice signaled to rise, walk around a pole 3 meters away, and return to their seats; the shorter of the 2 times required to complete this task was recorded. The 6MWT was measured according to the American Thoracic Society Statement ${ }^{16}$, where the longest distance walked in 6 minutes was measured. Study participants wore shoes suitable for walking and were instructed to attempt to cover the longest distance possible. The CPX was performed using a breath-by-breath method with a bicycle ergometer and respiratory metabolism measurement apparatus (manufactured by Minato Medical Science Co., Ltd.). The symptomatology maximum exercise load was measured using linear incremental 1-minute loads at 20 watts after resting for 3 minutes. The measurement indices included oxygen uptake, carbon dioxide output at an anaerobic metabolism threshold time, as well as the symptomatic limit maximum exercise load as calculated by the V-slope method.

The SF-36 (Japanese version) is a standardized self-management questionnaire to measure QOL ${ }^{17)}$. A higher score denotes a better QOL parameter across all indices. The SF-36 has a physical component summary (PCS), a mental component summary (MCS), and a role/social component summary (RCS); these were composed of 8 scales in total. The questionnaire has been validated for assessing changes in QOL in lung cancer research ${ }^{13}{ }^{18}$ ). In this study, we determined the deviation value of the score based on the nature of the questions and the national standard deviation.

Continuous variables are expressed as means and standard deviations. Longitudinal changes in physical function and QOL at different time points were analyzed by repeated measures of variance analysis, and the Dunnett method was used for the post hoc test. The relationships between each pre-surgically measured parameter and QOL, and that between the percent change in each measurement item and percent change in QOL score, were analyzed by Pearson's correlation analysis. Statistical analysis was performed using the SPSS software, version 19 (IBM, Chicago, IL, USA). The sample size required at least 24 patients to achieve a power of $80 \%$ with a significance level of 0.05 and measurement time of 4 .

\section{RESULTS}

Of the 47 subjects who initially registered, 8 who did not complete logistical requirements, 2 who developed metastasis and recurrence, and 1 who did not undergo surgery were excluded from the study. Ultimately, 36 patients participated. 
The characteristics of the participants who underwent VATS are shown in Table 1. There were no serious postoperative complications among the participants in the study; however, 6 patients experienced postoperative pain at the surgical incision site.

Table 2 shows the longitudinal changes in the physical function of the participants. In the respiratory function test, the forced vital capacity (FVC) decreased significantly from $2.79 \pm 0.631$ before surgery to $2.27 \pm 0.521(\mathrm{p}<0.05) 4$ weeks after surgery and to $2.39 \pm 0.52(\mathrm{p}<0.05) 12$ weeks after surgery. The percent FVC was significantly lower 4 and 12 weeks after surgery than before surgery. The forced expiratory volume (FEV) and percent FEV were also significantly decreased 4 and 12 weeks after surgery compared to before. There was no significant change in maximal oxygen consumption or in respiratory metabolic capacity over the entire period. Grip strength, TUG, and 6MWT were significantly decreased 1 week after surgery, but recovered to preoperative levels 4 weeks afterwards. Additionally, isometric knee extension strength decreased significantly 1 week after surgery, but remained significantly higher than pre-surgical values during the later time points.

Table 3 shows the longitudinal changes in QOL. The PCS score decreased significantly from $47.1 \pm 11.2$ before surgery to $35.9 \pm 15.0(\mathrm{p}<0.05) 1$ week after surgery, to $41.6 \pm 12.8(\mathrm{p}<0.05)$ 4 weeks after surgery, and to $43.2 \pm 10.3(\mathrm{p}<0.05) 12$ weeks after surgery. There was no significant difference in the MCS score across all time points. RCS scores decreased significantly from $45.0 \pm 13.6$ before surgery to $36.8 \pm 13.7(p<0.05) 1$ week after surgery, and decreased significantly further to $32.6 \pm 14.8$ $(p<0.05) 4$ weeks after surgery. RCS at 12 weeks after surgery was not significantly different from before surgery.

Table 4 shows the correlations between QOL and each physical function before surgery. Before surgery, there was a significant correlation between PCS and grip force $(r=0.403, p<0.05)$, knee extension strength $(\mathrm{r}=0.443, \mathrm{p}<0.01)$, TUG $(\mathrm{r}=-0.587, \mathrm{p}<0.01)$, and 6MWT $(\mathrm{r}=0.563, \mathrm{p}<0.01)$. However, there was no significant correlation with respiratory function or the cardiopulmonary exercise test result. Furthermore, there was no significant correlation between any physical function and MCS or RCS.

Table 5 shows the correlation between the percent change in each measurement item from before surgery to 12 weeks after surgery, as well as the percent change in QOL. There was no significant correlation between the percent change in PCS, MCS, and RCS and that in any of the parameters.

\section{DISCUSSION}

This prospective study aimed to objectively evaluate the physical functions of patients with lung cancer before and after VATS, including exercise tolerance and QOL, and to clarify the changes associated with these parameters after surgery. Our cohort was small and the results were preliminary; hence, our results should be interpreted with some caution. However, our findings suggest that the recovery of QOL and of physical function do not necessarily coincide. It was evident that the physical aspect of the QOL was suppressed until week 4 post-surgery, and gradually recovered to pre-surgical levels by week 12. It was also evident that the social role function aspect of the QOL was at its nadir at week 4 post-surgery, with a recovery observed in week 12 post-surgery. On the other hand, physical functions other than respiratory had recovered to pre-surgical levels by week 4 after surgery; knee extension strength was clearly stronger at that point than before surgery. Interestingly, there was no correlation between the percent changes in QOL and those in physical function. There is a dearth of studies on QOL and physical function in patients with lung cancer after surgical intervention ${ }^{19)}$. We hypothesized that a correlation exists between the recovery of physical function and that of QOL; however, our results disproved this hypothesis, as no significant correlation was found between the recovery of physical function and that of QOL.

Rizk et al. ${ }^{13)}$ clearly showed that the physical aspect of QOL in patients who underwent VATS decreased after surgery before gradually recovering. Sommer et al. ${ }^{20)}$ observed changes in the SF-36 physical function when comparing patients before surgery to 1 year after surgery. They reported that the physical role function decreases after surgery, but that rehabilitation provides a significant improvement even beyond the patients' pre-surgical statuses. In our study, a recovery was observed by week 12 ; however, there was a greater decrease in week 4 post-surgery than immediately after surgery. Schroyen et al. ${ }^{21)}$ 
Table 2. Chronological changes in physical function $(n=36)$

\begin{tabular}{|c|c|c|c|c|}
\hline & Baseline & 1 week & 4 weeks & 12 weeks \\
\hline & Mean \pm SD & Mean \pm SD & Mean \pm SD & Mean \pm SD \\
\hline \multicolumn{5}{|l|}{ Respiratory function } \\
\hline $\mathrm{FVC}(1)$ & $2.79 \pm 0.63$ & & $2.27 \pm 0.52^{*}$ & $2.39 \pm 0.52^{*}$ \\
\hline$\% \mathrm{FVC}(\%$ predicted $)$ & $98.0 \pm 15.0$ & & $79.4 \pm 13.4^{*}$ & $84.1 \pm 13.9^{*}$ \\
\hline $\mathrm{FEV}_{1.0}(1)$ & $2.13 \pm 0.51$ & & $1.77 \pm 0.45^{*}$ & $1.90 \pm 0.48^{*}$ \\
\hline$\% \mathrm{FEV}_{1.0}(\%$ predicted $)$ & $95.5 \pm 20.2$ & & $78.8 \pm 16.9^{*}$ & $84.8 \pm 17.6^{*}$ \\
\hline $\mathrm{FEV}_{1.0} / \mathrm{FVC}(\%)$ & $76.4 \pm 9.2$ & & $78.2 \pm 10.2$ & $79.3 \pm 9.6$ \\
\hline \multicolumn{5}{|l|}{ Cardiopulmonary exercise test (AT) } \\
\hline $\mathrm{VO}_{2}(\mathrm{ml} / \mathrm{kg} / \mathrm{min})$ & $12.0 \pm 2.4$ & & $11.7 \pm 2.4$ & $11.7 \pm 2.5$ \\
\hline $\mathrm{VCO}_{2}(\mathrm{ml} / \mathrm{kg} / \mathrm{min})$ & $11.4 \pm 2.6$ & & $11.3 \pm 2.5$ & $11.4 \pm 2.5$ \\
\hline \multicolumn{5}{|l|}{ Cardiopulmonary exercise test (Peak) } \\
\hline $\mathrm{VO}_{2}(\mathrm{ml} / \mathrm{kg} / \mathrm{min})$ & $16.2 \pm 4.2$ & & $15.2 \pm 4.1$ & $15.4 \pm 4.1$ \\
\hline $\mathrm{VCO}_{2}(\mathrm{ml} / \mathrm{kg} / \mathrm{min})$ & $17.0 \pm 5.4$ & & $16.4 \pm 5.4$ & $16.7 \pm 4.9$ \\
\hline \multicolumn{5}{|l|}{ Muscle strength } \\
\hline Hand grip (kg) & $30.5 \pm 9.1$ & $28.7 \pm 9.3^{*}$ & $29.7 \pm 8.8$ & $30.2 \pm 9.0$ \\
\hline Knee extension strength (\% BW) & $45.9 \pm 13.9$ & $42.8 \pm 14.1^{*}$ & $49.8 \pm 6.7^{*}$ & $51.3 \pm 18.4^{*}$ \\
\hline \multicolumn{5}{|l|}{ Walking ability } \\
\hline TUG (sec) & $6.1 \pm 1.6$ & $7.0 \pm 2.2^{*}$ & $6.3 \pm 1.7$ & $6.2 \pm 1.8$ \\
\hline $6 \mathrm{MWT}(\mathrm{m})$ & $523.2 \pm 116.3$ & $463.9 \pm 112.3^{*}$ & $516.5 \pm 115.0$ & $535.1 \pm 120.2$ \\
\hline
\end{tabular}

${ }^{*} \mathrm{p}<0.05$ vs. preoperative; FVC: forced expiratory volume; 1: liter; FEV: forced expiratory volume; AT: anaerobic threshold; $\mathrm{VO}_{2}$ : uptake; $\mathrm{VCO}_{2}$ : carbon output; W: mechanical power; TUG: timed up and go; 6MWT: 6-minute walking distance test; SD: standard deviation.

Table 3. Chronological changes as recorded on the short-form 36 health survey (SF-36) $(n=36)$

\begin{tabular}{|c|c|c|c|c|}
\hline & Baseline & 1 week & 4 weeks & 12 weeks \\
\hline & Mean \pm SD & Mean \pm SD & Mean \pm SD & Mean \pm SD \\
\hline \multicolumn{5}{|c|}{ SF-36 subscales (0-100 points) } \\
\hline $\mathrm{PF}$ & $81.8 \pm 13.6$ & $66.3 \pm 22.1^{*}$ & $73.7 \pm 21.2^{*}$ & $78.0 \pm 14.6$ \\
\hline $\mathrm{RP}$ & $78.8 \pm 24.3$ & $54.0 \pm 31.0^{*}$ & $51.5 \pm 28.4^{*}$ & $70.3 \pm 24.9$ \\
\hline $\mathrm{BP}$ & $76.7 \pm 23.4$ & $63.0 \pm 29.7^{*}$ & $59.4 \pm 27.3^{*}$ & $70.8 \pm 20.2$ \\
\hline GH & $62.0 \pm 17.0$ & $55.5 \pm 21.0$ & $58.5 \pm 16.3$ & $60.8 \pm 16.7$ \\
\hline VT & $65.9 \pm 17.8$ & $60.4 \pm 22.9$ & $54.5 \pm 25.3^{*}$ & $65.0 \pm 23.3$ \\
\hline SF & $85.6 \pm 16.3$ & $75.8 \pm 24.6$ & $66.3 \pm 25.9^{*}$ & $79.9 \pm 18.7$ \\
\hline RE & $79.3 \pm 26.1$ & $63.1 \pm 32.1^{*}$ & $61.1 \pm 34.3^{*}$ & $75.0 \pm 29.2$ \\
\hline MH & $66.1 \pm 18.7$ & $68.3 \pm 18.7$ & $63.6 \pm 23.6$ & $72.0 \pm 19.0$ \\
\hline \multicolumn{5}{|c|}{ SF-36 subscales (Scoring method based on national standard value) } \\
\hline $\mathrm{PF}$ & $44.7 \pm 9.8$ & $33.8 \pm 16.1^{*}$ & $38.9 \pm 15.3^{*}$ & $42.0 \pm 10.5$ \\
\hline $\mathrm{RP}$ & $44.4 \pm 12.9$ & $32.1 \pm 16.4^{*}$ & $29.9 \pm 15.1^{*}$ & $39.9 \pm 13.2$ \\
\hline $\mathrm{BP}$ & $51.3 \pm 10.5$ & $44.5 \pm 12.9^{*}$ & $43.6 \pm 12.2^{*}$ & $48.7 \pm 9.0$ \\
\hline $\mathrm{GH}$ & $49.5 \pm 9.1$ & $45.6 \pm 10.8$ & $47.6 \pm 8.7$ & $48.9 \pm 8.9$ \\
\hline VT & $51.6 \pm 9.1$ & $49.4 \pm 10.7$ & $45.7 \pm 13.0^{*}$ & $51.1 \pm 12.0$ \\
\hline $\mathrm{SF}$ & $49.6 \pm 8.4$ & $44.1 \pm 12.5^{*}$ & $39.6 \pm 13.3^{*}$ & $46.7 \pm 9.7$ \\
\hline $\mathrm{RE}$ & $45.7 \pm 13.0$ & $36.9 \pm 15.7^{*}$ & $36.6 \pm 17.2^{*}$ & $43.6 \pm 14.6$ \\
\hline MH & $47.0 \pm 10.0$ & $47.3 \pm 10.1$ & $45.7 \pm 12.6$ & $50.2 \pm 10.2$ \\
\hline \multicolumn{5}{|c|}{ SF-36 component summary score } \\
\hline PCS & $47.1 \pm 11.2$ & $35.9 \pm 15.0^{*}$ & $41.6 \pm 12.8^{*}$ & $43.2 \pm 10.3^{*}$ \\
\hline MCS & $52.7 \pm 9.6$ & $56.1 \pm 8.5$ & $53.5 \pm 9.4$ & $55.2 \pm 8.8$ \\
\hline RCS & $45.0 \pm 13.6$ & $36.8 \pm 13.7^{*}$ & $32.6 \pm 14.8^{*}$ & $42.0 \pm 13.5$ \\
\hline
\end{tabular}

$* \mathrm{p}<0.05$ vs. preoperative; PF: physical functioning; RP: physical role functioning; BP: bodily pain; GH: general health; VT: vitality; SF: social functioning; RE: emotional role functioning; MH: mental health; PCS: physical component summary; MCS: mental component summary; RCS: role/social component summary; SD: standard deviation. 
Table 4. Relationship between physical function and healthrelated QOL in preoperative $(\mathrm{n}=36)$

\begin{tabular}{lrrr}
\hline & PCS & MCS & RCS \\
\hline Respiratory function & & & \\
$\% \mathrm{FVC}$ & -0.17 & 0.02 & -0.14 \\
$\% \mathrm{FEV}_{1.0}$ & -0.16 & 0.02 & -0.13 \\
Cardiopulmonary exercise test (AT) & & & \\
$\mathrm{VO}_{2}$ & 0.10 & 0.14 & -0.04 \\
$\mathrm{VCO}_{2}$ & 0.04 & 0.03 & 0.01 \\
Cardiopulmonary exercise test (Peak) & & & \\
$\mathrm{VO}_{2}$ & 0.23 & 0.03 & 0.10 \\
$\mathrm{VCO}_{2}$ & 0.20 & -0.04 & 0.12 \\
Muscle strength & & & \\
Hand grip & $0.40^{*}$ & -0.05 & -0.09 \\
Knee extension strength & $0.44^{*}$ & -0.08 & 0.06 \\
Walking ability & & & \\
TUG & $-0.59^{*}$ & 0.17 & -0.14 \\
6MWT & $0.56^{*}$ & -0.13 & 0.14 \\
\hline
\end{tabular}

${ }^{*} \mathrm{p}<0.05$; QOL: quality of life; FVC: forced expiratory volume; $\mathrm{FEV}_{1.0}$ : forced expiratory volume; $\mathrm{VO}_{2}$ : uptake; $\mathrm{VCO}_{2}$ : carbon dioxideoutput; W: mechanical power; TUG: timed up and go; 6MWT: 6-minute walking distance test; PCS: physical component summary; MCS: mental component summary; RCS: role/ social component summary.
Table 5. Relationship between rate of change in physical function and rate of change in QOL from preoperative to postoperative 12 weeks $(n=36)$

\begin{tabular}{lrrr}
\hline & PCS & MCS & RCS \\
\hline Respiratory function & & & \\
\%FVC & 0.09 & 0.01 & -0.28 \\
$\quad \mathrm{FEV}_{1.0}$ & 0.03 & -0.07 & -0.12 \\
Cardiopulmonary exercise test (AT) & & & \\
$\quad \mathrm{VO}_{2}$ & -0.12 & 0.27 & -0.02 \\
$\mathrm{VCO}_{2}$ & -0.13 & 0.15 & -0.18 \\
Cardiopulmonary exercise test (Peak) & & & \\
$\mathrm{VO}_{2}$ & 0.05 & 0.17 & 0.01 \\
$\mathrm{VCO}_{2}$ & -0.11 & 0.23 & -0.05 \\
Muscle strength & & & \\
$\quad$ Hand grip & 0.18 & 0.01 & 0.18 \\
$\quad$ Knee extension strength & 0.08 & -0.11 & 0.02 \\
Walking ability & & & \\
TUG & 0.07 & 0.16 & -0.24 \\
6MWT & 0.07 & -0.10 & 0.09 \\
\hline
\end{tabular}

$* \mathrm{p}<0.05$; QOL: quality of life; FVC: forced expiratory volume; $\mathrm{FEV}_{1.0}$ : forced expiratory volume; $\mathrm{VO}_{2}$ : uptake; $\mathrm{VCO}_{2}$ : carbon dioxide output; W: mechanical power; TUG: timed up and go; 6MWT: 6-minute walking distance test; PCS: physical component summary; MCS: mental component summary; RCS: role/ social component summary.

reported that, in elderly patients with cancer, self-perception regarding aging and the effect of cancer influenced QOL, and that self-awareness of aging was also linked to physical health. The participants in our study were elderly, and it is possible that self-perceptions with respect to aging as well as their disease had a negative effect on QOL, as Schroyen et al. reported.

In general, muscular force and walking ability decrease in individuals as they age ${ }^{22)}$, and pulmonary rehabilitation is usually implemented before and after surgery ${ }^{12,19,23,24)}$. In a 12-week randomized comparison study of 53 patients postlobectomy, Arbane et al. ${ }^{23}$ ) observed no difference between patients who underwent usual care vs. those who received intervention (twice daily exercise training) 12 weeks after surgery. Conversely, Edvardsen et al. ${ }^{12}$ ) performed intensive training for their patients and found that post-surgical knee extension strength increased compared to that before surgery. In our study, we did not perform intensive training; however, knee extension strength was increased by week 12 after surgery compared to before surgery, and exercise tolerance also recovered rapidly to pre-surgical levels.

While the longitudinal indicators in our study are consistent with those of previous studies, there were no correlations between percent changes in QOL and those of physical function. This indicates that although early recovery of physical function is possible after VATS surgery, early recovery of QOL presents a greater challenge and is likely influenced by multiple factors.

The discrepancy between the recovery of physical function and that of QOL may be caused by differences between the levels of physical activity and physical function. Granger et al. ${ }^{25)}$ investigated physical activities in patients with lung cancer who were managed surgically and those who were not. They found that the non-surgically treated group did not experience a change in physical activity, while a significant decrease in physical activity was observed in surgically treated patients. Since the values for various SF-36 component summaries in our study decreased, it appears that the level of physical activity was lower despite achieving a recovery of physical function by week 4 after surgery (as Granger et al. observed).

Our study also investigated the relationship between physical function and QOL before surgery. Pompili et al. ${ }^{26)}$ found that the QOL of patients with lung cancer declined even before surgery; we also observed such a decrease before surgery. Moreover, the PCS before surgery was significantly correlated with performance tests. The fact that pre-surgical PCS did not correlate with respiratory and circulatory function, and that the MCS and RCS were not correlated with physical function, again suggests that QOL is governed by multiple factors. Therefore, it may be difficult to recover QOL quickly with a rehabilitation program focused on improving athletic performance. In recent years, hospitalization and intervention periods have become shorter; hence, it is necessary to verify the efficacy and efficiency of these intervention methods.

This study had some limitations. Although the purpose of this study was not to investigate post-surgical complications, there were several patients in whom it was impossible to evaluate physical function or QOL; moreover, the sample size was already quite small. QOL was likely to be even lower in these excluded patients. Furthermore, it was not possible to 
investigate the levels of physical activity, and we were thus unable to determine the relationship between physical activity, physical function, and QOL.

Our preliminary study highlights the fact that early recovery of physical function is possible after VATS, but that this does not necessarily correlate with early QOL recovery. Given these findings, we propose that physical therapists should examine methods that can promptly improve the QOL for lung cancer survivors who undergo VATS, not only to prevent postoperative complications but also to improve physical function.

\section{Funding}

The study was supported in part by JSPS KAKENHI Grant Number 25750240.

\section{Conflict of interest}

The authors declare no conflict of interest.

\section{ACKNOWLEDGEMENT}

The authors would like to thank the researchers who advised and the patients who participated in the research.

\section{REFERENCES}

1) de Boer AG, Taskila T, Ojajärvi A, et al.: Cancer survivors and unemployment: a meta-analysis and meta-regression. JAMA, 2009, 301: 753-762. [Medline] [CrossRef]

2) Shigemura N, Akashi A, Funaki S, et al.: Long-term outcomes after a variety of video-assisted thoracoscopic lobectomy approaches for clinical stage IA lung cancer: a multi-institutional study. J Thorac Cardiovasc Surg, 2006, 132: 507-512. [Medline] [CrossRef]

3) Yamashita S, Goto T, Mori T, et al.: Video-assisted thoracic surgery for lung cancer: republication of a systematic review and a proposal by the guidelines committee of the Japanese Association for Chest Surgery 2014. Gen Thorac Cardiovasc Surg, 2014, 62: 701-705. [Medline] [CrossRef]

4) Bendixen M, Jørgensen OD, Kronborg C, et al.: Postoperative pain and quality of life after lobectomy via video-assisted thoracoscopic surgery or anterolateral thoracotomy for early stage lung cancer: a randomised controlled trial. Lancet Oncol, 2016, 17: 836-844. [Medline] [CrossRef]

5) Kim SJ, Lee YJ, Park JS, et al.: Changes in pulmonary function in lung cancer patients after video-assisted thoracic surgery. Ann Thorac Surg, 2015, 99: 210-217. [Medline] [CrossRef]

6) Yan TD, Black D, Bannon PG, et al.: Systematic review and meta-analysis of randomized and nonrandomized trials on safety and efficacy of video-assisted thoracic surgery lobectomy for early-stage non-small-cell lung cancer. J Clin Oncol, 2009, 27: 2553-2562. [Medline] [CrossRef]

7) Garzon JC, Ng CS, Sihoe AD, et al.: Video-assisted thoracic surgery pulmonary resection for lung cancer in patients with poor lung function. Ann Thorac Surg, 2006, 81: 1996-2003. [Medline] [CrossRef]

8) Sakuraba M, Miyamoto H, Oh S, et al.: Video-assisted thoracoscopic lobectomy vs. conventional lobectomy via open thoracotomy in patients with clinical stage IA non-small cell lung carcinoma. Interact Cardiovasc Thorac Surg, 2007, 6: 614-617. [Medline] [CrossRef]

9) Igai H, Takahashi M, Ohata K, et al.: Surgical treatment for non-small cell lung cancer in octogenarians-the usefulness of video-assisted thoracic surgery. Interact Cardiovasc Thorac Surg, 2009, 9: 274-277. [Medline] [CrossRef]

10) McVay CL, Pickens A, Fuller C, et al.: VATS anatomic pulmonary resection in octogenarians. Am Surg, 2005, 71: 791-793. [Medline]

11) Edvardsen E, Skjønsberg OH, Holme I, et al.: High-intensity training following lung cancer surgery: a randomised controlled trial. Thorax, 2015, 70: 244-250. [Medline] [CrossRef]

12) Cavalheri V, Tahirah F, Nonoyama M, et al.: Exercise training undertaken by people within 12 months of lung resection for non-small cell lung cancer. Cochrane Database Syst Rev, 2013, 7: CD009955. [Medline]

13) Rizk NP, Ghanie A, Hsu M, et al.: A prospective trial comparing pain and quality of life measures after anatomic lung resection using thoracoscopy or thoracotomy. Ann Thorac Surg, 2014, 98: 1160-1166. [Medline] [CrossRef]

14) Schwartz RM, Yip R, Olkin I, et al. International Early Lung Cancer Action Program (I-ELCAP) investigators: Impact of surgery for stage IA non-small-cell lung cancer on patient quality of life. J Community Support Oncol, 2016, 14: 37-44. [Medline] [CrossRef]

15) Shumway-Cook A, Brauer S, Woollacott M: Predicting the probability for falls in community-dwelling older adults using the Timed Up \& Go Test. Phys Ther, 2000, 80: 896-903. [Medline]

16) ATS Committee on Proficiency Standards for Clinical Pulmonary Function Laboratories: ATS statement: guidelines for the six-minute walk test. Am J Respir Crit Care Med, 2002, 166: 111-117. [Medline] [CrossRef]

17) Fukuhara S, Bito S, Green J, et al.: Translation, adaptation, and validation of the SF-36 Health Survey for use in Japan. J Clin Epidemiol, 1998 , 51: 1037-1044. [Medline] [CrossRef]

18) Stigt JA, Uil SM, van Riesen SJ, et al.: A randomized controlled trial of postthoracotomy pulmonary rehabilitation in patients with resectable lung cancer. J Thorac Oncol, 2013, 8: 214-221. [Medline] [CrossRef]

19) Arbane G, Douiri A, Hart N, et al.: Effect of postoperative physical training on activity after curative surgery for non-small cell lung cancer: a multicentre randomised controlled trial. Physiotherapy, 2014, 100: 100-107. [Medline] [CrossRef]

20) Sommer MS, Trier K, Vibe-Petersen J, et al.: Perioperative Rehabilitation in Operable Lung Cancer Patients (PROLUCA): A Feasibility Study. Integr Cancer Ther, 2016, 15: 455-466. [Medline] [CrossRef]

21) Schroyen S, Marquet M, Jerusalem G, et al.: The link between self-perceptions of aging, cancer view and physical and mental health of older people with 
cancer: a cross-sectional study. J Geriatr Oncol, 2017, 8: 64-68. [Medline] [CrossRef]

22) Lauretani F, Russo CR, Bandinelli S, et al.: Age-associated changes in skeletal muscles and their effect on mobility: an operational diagnosis of sarcopenia. J Appl Physiol 1985, 2003, 95: 1851-1860. [Medline] [CrossRef]

23) Arbane G, Tropman D, Jackson D, et al.: Evaluation of an early exercise intervention after thoracotomy for non-small cell lung cancer (NSCLC), effects on quality of life, muscle strength and exercise tolerance: randomised controlled trial. Lung Cancer, 2011, 71: 229-234. [Medline] [CrossRef]

24) Pehlivan E, Turna A, Gurses A, et al.: The effects of preoperative short-term intense physical therapy in lung cancer patients: a randomized controlled trial. Ann Thorac Cardiovasc Surg, 2011, 17: 461-468. [Medline] [CrossRef]

25) Granger CL, McDonald CF, Irving L, et al.: Low physical activity levels and functional decline in individuals with lung cancer. Lung Cancer, 2014, 83: 292-299.

26) Pompili C, Salati M, Refai M, et al.: Preoperative quality of life predicts survival following pulmonary resection in stage I non-small-cell lung cancer. Eur J Cardiothorac Surg, 2013, 43: 905-910. [Medline] [CrossRef] 